\title{
Myocardial Cholinergic Signaling Changes with Age
}

\author{
EINAT BIRK AND R. KIRK RIEMER \\ Departments of Pediatrics [E.B.] and Obstetrics, Gynecology, and Reproductive Sciences [R.K.R.]. University of \\ California, San Francisco, San Francisco, California 94143-0556
}

\begin{abstract}
We examined the linkage of cholinergic receptors to the phosphoinositide signaling pathway to elucidate one facet of the autonomic response mechanism in fetal and adult sheep. Cholinergic stimulation with carbachol increases the production of ${ }^{3} \mathrm{H}$-inositol mono-, bis-, and trisphosphates in a time- and concentrationdependent manner in both fetal and adult myocardium. However, the maximal stimulation of inositol polyphosphates above basal activity was much greater in fetal (120 $\pm 11 \%$ ) than in adult $(20 \pm 7 \%)$ myocardium (mean \pm SEM). Saturation binding analysis of myocardial muscarinic receptors using ${ }^{3} \mathrm{H}$-N-methylscopolamine revealed significantly higher receptor concentration in fetal (240 \pm $25 \mathrm{fmol} / \mathrm{mg}$ protein) than in adult $(78 \pm 15 \mathrm{fmol} / \mathrm{mg}$ protein) myocardium (mean $\pm \mathrm{SEM}$ ). Binding competition studies revealed a pattern of selectivity-atropine $<4$ diphenylacetoxy- $\mathrm{N}$-methylpiperidine methiodide $<$ pirenzepine $\leq$ (4-hydroxy-2-butynyl)-1-trimethylammonium m-chlorocarbanilate chloride $\leq 11-2][2-[$ (diethylamino)methyll-1-piperidinyl]acetyl]-5, 11-dihydro-6H-pyrido[2, 3-b][1,4]benzodiazepine-6-one 116-compatible with the presence of muscarinic receptor (MR)2, MR3, and/or MR5 subtypes. Receptor subtype determination by Northern blot analysis revealed $m R N A$ specific for the MR2 subtype in both fetal and adult myocardium, although expression was greater in fetal heart. We conclude that decreases in MR2 subtype protein and mRNA levels parallel the agerelated decrease in carbachol-stimulated PLC activity. Our studies demonstrate differences between fetal and adult myocardium in the concentration of muscarinic cholinergic receptors and their linkage to a putative calcium mobilizing signaling pathway and suggest that this pathway may play a different role in the fetus than in the adult. The physiologic significance of this age-dependent change in cholinergic-linked signaling response of the myocardium is not yet known. (Pediatr Res 31: 601-605, 1992)
\end{abstract}

\section{Abbreviations}

$\left[{ }^{3} \mathrm{H}\right] \mathrm{NMS},\left[{ }^{3} \mathrm{H}\right] \mathrm{N}$-methylscopolamine

DAG, diacylglycerol

IP3, inositol 1,4,5 trisphosphate

IP, mixed inositol polyphosphates

MR, muscarinic receptor

PI, phosphatidylinositol

4-DAMP, 4-diphenylacetoxy- $\mathrm{N}$-methylpiperidine methiodide

AFDX 116, 11-2[[2-[(diethylamino)methyl]-1-piperidinyl]

Received October 22, 1991; accepted February 4, 1992

Correspondence and reprint requests: R. Kirk Riemer, Ph.D., Department of Obstetrics, Gynecology and Reproductive Sciences, Box 0550, Room 1462 HSE University of California. San Francisco, San Francisco, CA 94143-0550.

Supported by a Grant in Aid from the American Heart Association, California Affiliate $(89-113)$ to R.K.R.
acetyl]-5,11-dihydro-6H-pyrido[2,3-b][1,4]benzodiazepine-6-one

McN-A-343, (4-hydroxy-2-butynyl)-1-trimethylammonium $\mathrm{m}$-chlorocarbanilate chloride

PLC, phosphoinositide-specific phospholipase C

CHO, Chinese hamster ovary

Fetal myocardial contractile proteins (1) and adrenergic receptors change during development. However, little information is available regarding the biochemical or physiologic role of MR during mammalian myocardial development. MR activation has negative chronotropic and inotropic effects in adult heart. The biochemical responses to muscarinic stimulation in the heart include a reduction in cAMP concentration (2-4), an increase in the hydrolysis of phosphoinositides (5), and activation of potassium (6) and sodium (7) channels. The inhibitory myocardial effects of muscarinic stimulation on heart rate and force development have previously been attributed to the inhibition of adenylyl cyclase activity $(2,3)$. Although the effects of phosphoinositide hydrolysis are not clear, recent studies have associated it with positive inotropic effect $(8,9)$ as well as negative inotropy (10). The products of PI 4,5 bisphosphate hydrolysis are the two second messengers IP3 and 1,2 DAG. Inositol trisphosphate triggers intracellular $\mathrm{Ca}^{++}$release and initiates $\mathrm{Ca}^{++}$influx, and DAG drives the $\mathrm{Ca}^{++}$-dependent activation of protein kinase $\mathrm{C}$, which has several myocardial substrates (11). In recent years, it has become apparent that the MR are a family of at least five gene products with distinct primary structures, heterogenous ligand binding properties, and diverse functions $(12,13)$. They also display tissue-specific expression. Only the MR2 subtype has been detected in the human and rat heart. However, the MR1 subtype is thought to be the predominant one in chick heart (14). Using DNA transfection techniques in CHO cells, the MR2 subtype induces the inhibition of adenylyl cyclase activity, although at higher receptor concentrations it was shown to induce phosphoinositide hydrolysis (15).

Our goals in this study were to compare the ligand-binding properties and linkage to a biochemical response of fetal and adult myocardial MR. We found that both fetal and adult heart express MR2 and exhibit carbachol-stimulated IP production. However, receptor density and IP production were approximately 3 -fold greater in fetal compared with adult myocardium.

\section{MATERIALS AND METHODS}

Immediately after euthanasia, the hearts of fetal (90-140 $\mathrm{d}$ gestation) lambs, 1-mo-old lambs, and adult sheep were excised, dissected free of major blood vessels and epicardial fat, and rinsed in Krebs-Henseleit physiologic salt solution (16) continuously aerated with $95 \% \mathrm{O}_{2}, 5 \% \mathrm{CO}_{2}$ to maintain a $\mathrm{pH}$ of 7.4. The ventricular tissue was dissected free of remaining con- 
nective tissue and vessels, minced into $\sim 1$-mm cubes, maintained at room temperature in Krebs-Henseleit solution under continuous aeration, and used within $1 \mathrm{~h}$ or immediately frozen in liquid nitrogen (without mincing) for later biochemical analysis.

Assay of agonist-stimulated PLC activity. The methods for assay of PLC activity in minced muscle tissue have been published previously (16). Briefly, aliquots of minced tissue $(1 \times 1$ mm cubes, $0.1 \mathrm{~g}$ wet weight) were incubated with $\left[{ }^{3} \mathrm{H}\right]$ myoinositol (New England Nuclear, Boston, MA; $16 \mu \mathrm{Ci} / \mathrm{mL}$ ) in a total volume of $200 \mu \mathrm{L}$ of Krebs-Henseleit buffer at $37^{\circ} \mathrm{C}$ for $2 \mathrm{~h}$ to label the PI pool. The tissue was then transferred to fresh medium that contained $10 \mathrm{mM} \mathrm{LiCl}$ (to inhibit inositol monophosphatase), the agonist added, and incubation carried out for $30 \mathrm{~min}$ unless otherwise indicated. Incubations were terminated by the addition of ice-cold $\mathrm{CHCl} 3 / \mathrm{MeOH}(1: 2)$ and the samples stored at $-20^{\circ} \mathrm{C}$ until extracted. The aqueous phase containing IP was loaded onto $1-\mathrm{mL}$ columns of Dowex $1 \mathrm{X} 8$ resin (formate form). IP3 metabolites were eluted sequentially with different concentrations of ammonium formate in $0.1 \mathrm{M}$ formic acid $(0.2 \mathrm{M}$, inositol monophosphates; $0.4 \mathrm{M}$, inositol bisphosphates; $1 \mathrm{M}$, inositol tris- and tetrakisphosphates) or using $1 \mathrm{M}$ ammonium formate $/ 0.1 \mathrm{M}$ formic acid to elute all of these metabolites as a pool. The elution conditions were validated by chromatography of radioactive reference standards. The samples were counted for radioactivity, and the data expressed as the average change in response of duplicate incubations relative to vehicle controls.

$M R$ binding of $\left[{ }^{3} H\right] N M S$. Membrane particulate fractions were prepared by homogenization and differential centrifugation as previously described (17). The particulates were frozen in small aliquots at a protein concentration of $3-5 \mathrm{mg} / \mathrm{mL}$ using liquid $\mathrm{N}_{2}$ and stored at $-80^{\circ} \mathrm{C}$ until used. Binding saturation analysis was used to determine MR concentration and affinity. Cardiac membrane particulates ( $1 \mathrm{mg}$ protein $/ \mathrm{mL}$ ) were incubated at $30^{\circ} \mathrm{C}$ for $90 \mathrm{~min}$ in a total volume of $200 \mu \mathrm{L}$ of TM buffer [ 50 $\mathrm{mM}$ Tris ( $\mathrm{pH} 7.4$ ), $20 \mathrm{mM} \mathrm{MgCl}_{2}$ ] with increasing concentrations $(0.1-10 \mathrm{nM})$ of the muscarinic cholinergic antagonist $\left[{ }^{3} \mathrm{H}\right] \mathrm{NMS}$. Nonspecific binding was determined in parallel incubations containing $1 \mu \mathrm{M}$ atropine to compete for specific binding. At the end of the incubation, $5 \mathrm{~mL}$ of ice-cold TM buffer was added, and the samples were filtered through Whatman GF/C filters under low vacuum to separate free and bound $\left[{ }^{3} \mathrm{H}\right]$ NMS. After three additional $5-\mathrm{mL}$ washes, the filters were dried and the radioactivity counted by liquid scintillation spectrophotometry (Beckman Instruments Inc., Palo Alto, CA). Specific binding was analyzed as a function of free ligand using an iterative nonlinear curve-fitting program executed on an HP9825B computer, which fits untransformed data to a rectangular hyperbola (18). The data obtained are the total number of receptors (with SD) and the affinity (with SD).

Competitive binding studies with muscarinic subtype-selective ligands. Competition isotherms were constructed for nonradioactive muscarinic agonists and antagonists by incubating membrane particulates with $\left[{ }^{3} \mathrm{H}\right] \mathrm{NMS}$ and increasing concentrations of competitors. The competitors used were atropine (Sigma Chemical Co., St. Louis, MO); pirenzepine (Sigma Chemical Co.), an antagonist with higher affinity for MR1 versus MR2; 4DAMP (Research Biochemicals, Natick, MA), a MR2 antagonist, the antagonist AFDX 116 (Boehringer Ingelheim, Ridgefield, CT; MR2 = MR4 > MR1); and McN-a-343 (Research Biochemicals), an MR1 agonist. The incubation is conducted essentially as for saturation analysis, except the concentration of $\left[{ }^{3} \mathrm{H}\right] \mathrm{NMS}$ is fixed at $1 \mathrm{nM}$ and varying concentrations of competing ligand are used (14 concentration points assayed in duplicate). The competitor concentration $\left(\mathrm{IC}_{50}\right)$, which competes for half maximal binding to a given affinity site, is determined using an iterative, nonlinear curve-fitting program that quantitates the change in $k_{d}$ as a function of the concentration of competing ligand [in the presence of inhibitor $\left.(\mathrm{I}), \mathrm{k}_{\mathrm{d}}=1+\mathrm{I} / \mathrm{K}_{\mathrm{I}}\right]$. The affinity constant of the competing ligand $\left(\mathrm{K}_{\mathrm{I}}\right)$ was calculated from the $\mathrm{IC}_{50}$ using the relation of $\mathrm{K}_{\mathrm{I}}=\mathrm{IC}_{50} / 1+\mathrm{lf} / \mathrm{k}_{\mathrm{d}}$, where $\mathrm{Lf}$ is the free ligand concentration (19). In addition to the $\mathrm{K}_{\mathrm{l}}$, the ratio of site number of a given affinity to total number of occupied sites also is quantitated, allowing the estimation of multiple site interactions and the standard error of the estimated affinity for each site.

Northern analysis of myocardial mRNA. Total mRNA was prepared from frozen myocardium of $135 \mathrm{~d}$ gestational age sheep fetus, 2 nd trimester aborted human fetus, and adult sheep by the method of Chirgwin et al. (20). Total RNA $(12 \mu \mathrm{g})$ was denatured by formaldehyde, separated by electrophoresis through a $1.2 \%$ agarose gel, and transferred to nitrocellulose membrane (NitroPlus 2000; Micron Separations Inc., Westborough, MA) (21). Integrity and amount of RNA loaded were confirmed by staining duplicate samples with ethidium bromide. The filter was baked and then prehybridized in Northern prehybridization solution containing $50 \%$ (vol/vol) formamide at $65^{\circ} \mathrm{C}(22)$. DNA probes complimentary to the human MR1, MR2, and MR4 subtype mRNA (15) were subcloned in pMSVneo and expressed in Escherichia coli strain DH5 $\alpha$ or HB101. The cDNA probe sequence was excised from the vector using restriction endonucleases and purified by agarose gel electrophoresis in $0.7 \%$ low melting point agarose (SeaPlaque; FMC Bioproducts, Rockland, $\mathrm{ME})$. The probe was labeled directly from agarose with $\left[{ }^{32} \mathrm{P}\right]$ deoxycytidine triphosphate by the random primers method using a prepared reagent kit according to the manufacturer's directions (Pharmacia LKB Biotechnology, Piscataway, NJ). Hybridization was carried out under the same conditions as was the prehybridization. The membrane was then washed at room temperature in $2 \times$ SSC (standard saline citrate) followed by $0.5 \times$ SSC and exposed to $\mathrm{x}$-ray film (Kodak X-OMAT AR) at $-70^{\circ} \mathrm{C}$ for $72 \mathrm{~h}$. Equal loading of the RNA samples was verified by ethidium bromide staining of replicate lanes run in the same gel. We found this to be far more reliable than stripping and reprobing of the filters with so-called control probes such as $\beta$-actin.

Statistical analysis. The data are presented as mean values \pm SEM. Statistical significance of differences was determined by the unpaired $t$ test. A confidence level of $95 \%$ was the criterion for significance.

\section{RESULTS}

PLC activation in fetal and adult myocardial minces. Addition of carbachol $(1 \mathrm{mM})$ increased the production of inositol mono-, bis-, and tris- plus tetrakisphosphates in a linear fashion over time (Fig. 1).

Carbachol produced an increase of $120 \pm 6 \%$ over the basal value of IP in fetal myocardium (Fig. 2) compared with $19 \pm 1 \%$ $(n=4)$ in adult myocardium. The maximal increase in myocar-

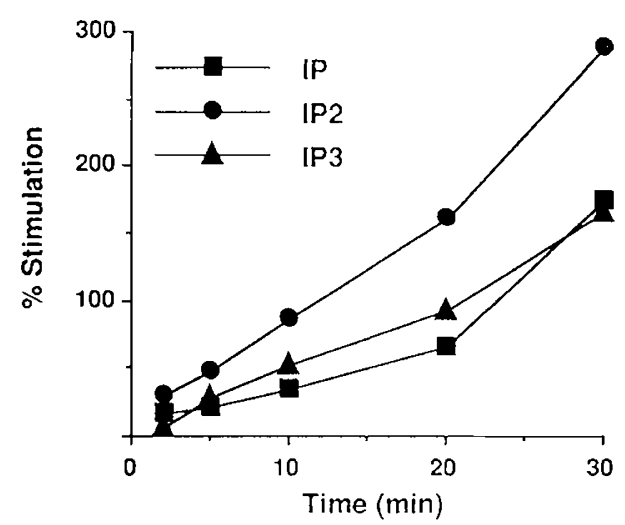

Fig. 1. Production of inositol phosphate metabolites in minced myocardium of $128 \mathrm{~d}$ gestation sheep fetus: time course for the production of inositol mono- (IPI), bis- (IP2), and tris- plus tetrakisphosphates (IP3) (\% stimulation above basal) in response to $1 \mathrm{mM}$ carbachol (data are presented as averages of duplicate incubations from a single experiment). 


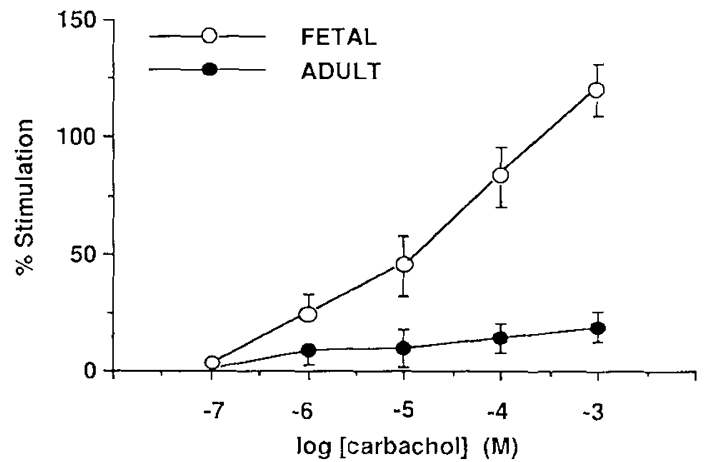

Fig. 2. Inositol phosphate production in minced myocardium: doseresponse curve for the production of pooled inositol phosphates (\% stimulation above basal) in response to carbachol in fetal and adult myocardium (data are presented as means \pm SEM; four animals were studied in each group).

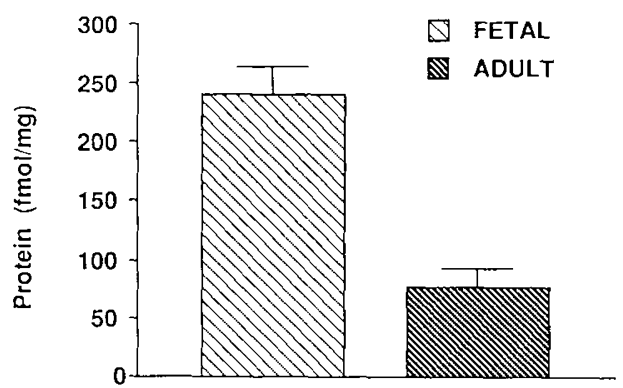

Fig. 3. Myocardial MR concentrations: results of saturation analysis with $\left[{ }^{3} \mathrm{H}\right] \mathrm{NMS}$ quantitating both maximal capacity and binding affinity. The maximal capacity was significantly reduced in adult compared with fetal myocardium $(p<0.005)$. Receptor affinity $\left(k_{d}\right)$ for $\left[{ }^{3} H\right] N M S$ was approximately $1 \mathrm{nM}$ and did not vary among the groups (representative experiment).

dium from 1 -mo-old lambs was $75 \pm 8 \%$ over the basal value ( $n$ $=3$ ).

Saturation binding studies with $\left[{ }^{3} H\right] N M S$. The binding of $\left[{ }^{3} \mathrm{H}\right]$ NMS to fetal and adult heart membrane preparations was saturable and of the same high affinity $(0.8-1.0 \mathrm{nM})$ at both ages. The maximal binding capacity was three times higher in nearterm fetal membranes than in adult. Near-term fetal myocardium contained three times the concentration of MR present in the adult $(226 \pm 22$ versus $76 \pm 11 \mathrm{fmol} / \mathrm{mg}$ protein, $p=0.001$, $n=4$ ) (Fig. 3).

Analysis of $M R$ subtypes by binding competition. Because the myocardium of most mammalian species is thought to express the MR2 subtype, we sought to determine whether this was also true of sheep myocardium. To characterize the MR2 subtype, we constructed binding isotherms using several subtype-selective muscarinic ligands as competitors for $\left[{ }^{3} \mathrm{H}\right] \mathrm{NMS}$ binding to fetal and adult heart membranes. The results of these studies are summarized in Table 1. We found that the receptors present in fetal and adult myocardium have the same characteristics in terms of rank order of affinity for several ligands: atropine $<4$ DAMP $<$ pirenzepine $\leq$ AFDX $116=\mathrm{McN}-\mathrm{A}-343$. These data support the presence of the MR2 subtype in both fetal and adult sheep myocardium. However, the fetal heart showed complex competition isotherms for AFDX 116, suggesting the possible presence of MR3 and MR5 subtypes as well as the MR2 subtype. Adult heart showed a single site fit for AFDX 116, suggesting the presence of MR2. The high affinity interaction of the cholinergic agonist carbachol was apparent in both fetal and adult preparations, and for both ages the "guanosine triphosphate shift" to a lower affinity state was similar.

Northern analysis of myocardial MR2 $m R N A$. Because the available ligands are not sufficiently selective for binding com-
Table 1 . Affinity constants for $\left[{ }^{3} H\right] N M S$ binding*

\begin{tabular}{lcc}
\multicolumn{1}{c}{ Competing ligand } & Fetal & \multicolumn{1}{c}{ Adult } \\
\cline { 1 - 3 } Atropine & $1.2( \pm 5 \%)$ & $2.6( \pm 7 \%)$ \\
4-DAMP & $13( \pm 6 \%)$ & $11( \pm 8 \%)$ \\
Pirenzepine & $854( \pm 21 \%)$ & $371( \pm 17 \%)$ \\
AFDX 116 & $515( \pm 39 \%)$ & \\
& $6554( \pm 37 \%)$ & $673( \pm 10 \%)$ \\
McN-A-343 & $549( \pm 37 \%)$ & \\
& $10660( \pm 51 \%)$ & $1100( \pm 30 \%)$ \\
Carbachol & $640( \pm 24 \%)$ & $72( \pm 72 \%)$ \\
& $52400( \pm 33 \%)$ & $19600( \pm 59 \%)$ \\
Carbachol + GPPNHP† & $54200( \pm 21 \%)$ & $53600( \pm 29 \%)$ \\
\hline
\end{tabular}

* Binding selectivity for sheep myocardial MR: the affinity constants for the competing ligands are compatible with the presence of MR2, MR3, MR4, and MR5 subtypes. The data are the best fit affinity values in $\mathrm{nM}$ ( \pm standard error of the estimate expressed as \%) for the competing ligands.

$\dagger$ GPPNHP, guanosine imidodiphosphate. The concentration of GPPNHP in the assay was $0.1 \mathrm{mM}$.

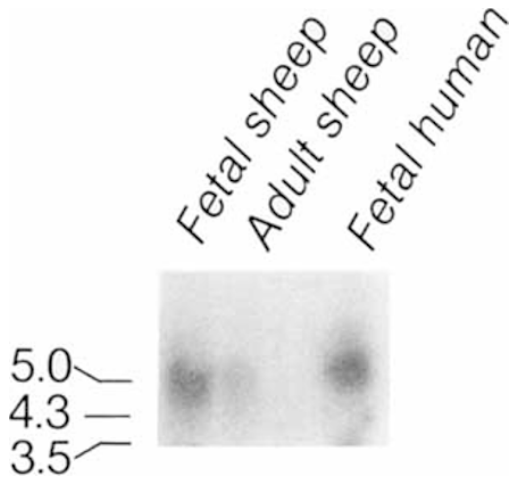

Fig. 4. Autoradiogram of a Northern blot showing MR2 expression in myocardium of 135-d fetal sheep, adult sheep, and fetal human: each lane was loaded with $12 \mu \mathrm{g}$ RNA. The blot was exposed for $72 \mathrm{~h}$ at $-70^{\circ} \mathrm{C}$. The expression of mRNA for MR2 was greater in the fetal sheep (and fetal human myocardium) than in adult sheep (representative experiment).

petition studies to conclusively prove the existence of a particular MR subtype and our data suggested the novel possibility that the MR2 subtype was coupled to PLC activation, we examined MR subtype mRNA expression in sheep myocardium. We used several available cDNA probes selective for cloned MR subtypes to identify the subtypes expressed in the two groups. Using Northern blot analysis of total RNA, we found that the only message that we could positively detect was the message for the MR2 subtype in both fetal and adult myocardium. Moreover, we found that the relative abundance of the MR2-specific message was far greater in the fetal sheep tissue than in the adult sheep (Fig. 4). As an internal control for the human cDNA probe, we also analyzed RNA samples from human myocardium. The intensity of the signal from midgestational human fetal myocardium was similar to that of fetal sheep. Thus, we can confirm that indeed there is an increased expression of the MR2 gene in fetal myocardium compared with adult. Preliminary results with MR1, MR3, and MR4 cDNA probes failed to reveal their expression in either fetal or adult sheep myocardium, suggesting the need for a more sensitive method of analysis of these mRNA.

\section{DISCUSSION}

In this study, we found that the ability to stimulate IP production with carbachol was significantly higher in fetal myocardium than in adult myocardium. The concentration of MR in fetal myocardium was also significantly higher, as has been reported 
in rat heart (23). Binding competition studies indicate the presence of the MR2 subtype and the probable absence of MR1. However, the presence of other MR subtypes in fetal myocardium cannot be ruled out because the ability to discriminate between receptor subtypes in radioligand binding studies depends on the concentration (or relative proportion) of the subtypes. Thus, the heterogeneity apparent in the fetal competition curves may also exist in the adult, but it was not detected by the methods used. The putative MR1-selective agonist McN-A-343 had two affinity classes similar to those of the nonselective agonist carbachol in fetal myocardium. However, the binding affinity for McN-A-343 was of a single affinity class in adult myocardium. Because this affinity was intermediate relative to the two affinity classes in fetal preparations, this also suggests the presence of subtype heterogeneity in fetal versus adult myocardium, although MR subtype assignation is not possible. Finally, the highest affinity binding for this agonist was 500- to 1000-fold greater than that reported for MR1 and MR3 in transfected CHO cells, supporting our conclusion that MR1 (and MR3) may not be present in sheep myocardium. Coupling of both fetal and adult MR to guanine nucleotide-binding proteins is demonstrated by the similar ability of a guanosine triphosphate analogue to reduce the high affinity binding of carbachol (Table 1). Thus, the receptor populations measured at either age appear to be able to interact with $\mathrm{G}$ protein coupled effectors. Inasmuch as currently available agents cannot clearly discriminate among the known receptor subtypes, we carried out the mRNA expression studies and found that both adult and fetal myocardium express MR2. The MR2-specific transcripts were significantly more abundant in the fetal tissue, a finding that correlated with the higher receptor concentration and IP production found in the fetus. This finding also indicates that the age-related change in myocardial MR2 concentration does not require regulation at the translational level.

Earlier studies by other investigators have indicated that there were only two MR subtypes, MR1 and MR2, which were coupled, respectively, to PLC activation and inhibition of adenylyl cyclase. Five unique genes for MR have subsequently been identified (13). Among these five MR, two, MR2 and MR4, are thought normally to be negatively coupled to adenylyl cyclase, and the other three are thought to be coupled to PLC in their native state (24). The coupling of MR2 to PLC activation in any normal tissue has not been previously reported. However, a study performed in CHO cells transfected with a single MR subtype showed that the MR2 subtype is capable of coupling to both cAMP formation and PI hydrolysis, although the latter response required a much higher concentration of carbachol (15). The increased number of MR found in fetal myocardium would be expected to enable the production of a larger (and therefore measurable) amount of IP in fetal myocardium compared with adult myocardium. However, the results do not exclude the possibility that fetal and adult MR2 differ in the efficiency with which they couple to PI; nor do they exclude the possibility that fetal myocardium contains a small population of MR1 or MR4 not detected by our competition studies but sufficient to increase IP production in response to carbachol.

The physiologic significance of the increased density of MR2 in fetal myocardium is not known. Assuming that increased receptor density and signaling translates into enhanced response, then the question is really what the physiologic advantage is to the fetus to be able to negatively regulate force development. The answer to such a question must await further investigation. The significance of increased muscarinic IP production in fetal versus adult myocardium remains unclear. In adult myocardium, muscarinic stimulation results in a negative inotropic effect (10), which has been largely attributed to the MR-stimulated decrease in cAMP production (25). However, muscarinic agonists such as acetylcholine or carbachol can produce either a positive or a negative inotropic effect on the heart $(8,26)$, depending on agonist concentration. In general, low agonist concentration causes predominantly negative inotropism, and vice versa. Both effects are diminished by atropine, leading to the conclusion that they are executed through the activation of the muscarinic receptor. Thus, the significance of enhanced second messenger production is difficult to assess until its relation to myocardial function is clearly understood.

The myocardial role of PI hydrolysis and its resulting second messengers, IP3 and DAG, is not well defined. In a variety of other cell types, IP3 acts as a calcium-mobilizing second messenger (27-30). DAG activates protein kinase $\mathrm{C}$, which has several substrate proteins in the heart, although its physiologic effect in the myocardium is not known. The heart differs from striated and smooth muscles in that CAMP production is coupled to increased force development, rather than relaxation. Perhaps IP3 serves a different function in the heart than in other muscles. It should be borne in mind that IP3 is linked to hormonal secretion in many cell types, and it is therefore possible that IP3 production in heart tissue mediates the release of unknown substances that have equally unknown physiologic effects.

Recent studies demonstrated that muscarinic activation can mediate positive inotropic effect in ventricular myocardium of guinea pig when high concentrations of carbachol were used (8). It was also shown that carbachol can mediate the production of inositol phosphates and induce positive inotropic effect in rat atria when its effect to lower CAMP is blocked by pertussis toxin (9). These studies indicate a relation between muscarinic stimulation, PI breakdown, and positive inotropism. However, in both studies the MR subtype identity was limited to binding competition analyses, which suggested that either MR1 or MR2 could be involved.

In conclusion, we have demonstrated that fetal myocardium has a greater capacity to activate MR-linked PLC than adult myocardium, and that fetal myocardium contains higher concentrations of MR than adult myocardium. We have also shown that the MR2 subtype is expressed in both fetal and adult myocardium, and that greater expression correlates with greater receptor concentration and greater second messenger production. Future research may be aimed at resolving the question of whether these findings carry physiologic significance and can be one of the elements determining the difference between adult and fetal myocardial contractility in response to autonomic effectors.

Acknowledgments. The authors thank Drs. Michael Heyman and Abraham Rudolph, and their research assistant, Christine Roman, for providing access to their control animals so they could be used in this study. We thank Dr. Avi Ashkenazi and Dr. Ernest Peralta (Genentech, San Bruno, CA) for generously providing the cDNA probes for the MR2 receptor and the MR1 and MR4 receptors, respectively.

\section{REFERENCES}

1. Lompre AM, Nadal-Ginard B, Mahdavi V 1984 Expression of the cardiac ventricular $\alpha$ - and $\beta$-myosin heavy chain genes is developmentally and hormonally regulated. $J$ Biol Chem 259:6437-6446

2. George WJ, Wilkerson RD, Kadowitz PJ 1973 Influence of acetylcholine on contractile force and cyclic nucleotide levels in the isolated perfused rat heart. J Pharmacol Exp Ther 184:228-235

3. Hazeki O, Ui M 1981 Modification by islet-activating protein of receptor mediated regulation of cyclic AMP accumulation in isolated rat heart cells. J Biol Chem 256:2856-2862

4. Masters SB, Martin MW, Harden TK, Brown JH 1985 Pertussis toxin does not inhibit muscarinic-receptor-mediated phosphoinositide hydrolysis or calcium mobilization. Biochem J 227:933-937

5. Brown SL, Brown JH 1983 Muscarinic stimulation of phosphatidylinositol metabolism in atria. Mol Pharmacol 24:351-356

6. Pfaffinger PJ, Martin JM, Hunter DD, Nathanson NM, Hille B 1985 GTP binding proteins couple cardiac muscarinic receptors to a $\mathrm{K}$ channel. Nature 317:536-538

7. Cohen-Armon M, Sokolovsky M 1986 Interactions between the muscarinic receptors, sodium channels, and guanine nucleotide-binding protein $(s)$ in rat atria. J Biol Chem 261:12498-12505

8. Korth M, Kühlkamp V 1987 Muscarinic receptors mediate negative and 
positive inotropic effects in mammalian ventricular myocardium: differentiation by agonist. Br J Pharmacol 90:81-90

9. Imai S, Ohta H 1988 Positive inotropic effects induced by carbachol in rat atria treated with islet-activating protein (IAP) - association with phosphatidylinositol breakdown. Br J Pharmacol 94:347-354

10. Deighton NM, Motomura S, Borquez D, Zerkowski H-R, Doetsch N. Brodde O-E 1990 Muscarinic cholinoceptors in human heart: demonstration, subclassification, and distribution. Naunyn-Schmiedebergs Arch Pharmacol $341: 14-21$

11. Noland Jr TA, Raynor RL, Kuo JF 1989 Identification of sites phosphorylated in bovine cardiac troponin $I$ and tropinin $T$ by protein kinase $C$ and comparative substrate activity of synthetic peptides containing the phosphorylation sites. J Biol Chem 264:20778-20785

12. Peraita GP, Ashkenazi A, Winslow JW, Smith DH, Ramachandran J, Capon DJ 1987 Distinct primary structures, ligand binding properties and tissuespecific expression of four human muscarinic acetylcholine receptors. EMBO J 6:3923-3929

13. Dörje F, Wess J, Lambrecht G. Tacke R, Mutschler E, Brann MR 1991 Antagonist binding profiles of five cloned human muscarinic receptor subtypes. J Pharmacol Exp Ther 256:727-733

14. Brown JH, Goldstein D. Brown-Masters S 1985 The putative MI muscarinic receptor does not regulate phosphoinositide hydrolysis. Mol Pharmacol 27:525-531

15. Peralta GP, Ashkenazi A, Winslow JW, Ramachandran J, Capon DJ 1988 Differential regulation of PI hydrolysis and adenylyl cyclase by muscarinic receptor subtypes. Nature 334:434-437

16. Riemer RK. Roberts JM 1987 Estrogen increases adrenergic but not cholinergic mediated production of inositol phosphates in rabbit uterus. Mol Pharmacol 32:663-668

17. Riemer RK, Goldfien AC, Roberts JM 1986 Rabbit myometrial oxytocin receptors and in vitro contractile response: abrupt changes at term and the role of eicosanoids. Endocrinology 119:699-709
18. Murlas C, Nadel JA, Roberts JM 1982 The muscarinic receptors of airway smooth muscle. J Appl Physiol 52:1084-1091

19. Cheng Y, Prusoff WH 1973 Relationship between the inhibition constant (Ki) and the concentration which causes 50 percent inhibition (150) of an enzymatic reaction. Biochem Pharmacol 22:3099-3108

20. Chirgwin JM, Przybyla AE. MacDonald RJ, Rutter WJ 1979 Isolation of biologically active ribonucleic acid from sources enriched in ribonucleases. Biochemistry 18:5294-5299

21. Sambrook J, Fritsch EF, Maniatis T 1989 Molecular Cloning, 2nd Ed. Cold Spring Harbor Laboratory, Cold Spring Harbor, New York

22. Ausubel FM, Brent R, Kingston RE, Moore DD, Seidman JG, Smith JA, Struhl K (eds) 1989 Current Protocols in Molecular Biology. Greene Publishing Associates and John Wiley \& Sons, New York

23. Nedoma J, Slavíková J, Tucek S 1986 Muscarinic acetylcholine receptors in the heart of rats before and after birth. Pflugers Arch 406:45-50

24. Barnard EA 1988 Separating receptor subtypes from their shadows. Nature 335:301-302

25. Löffelholz K, Pappano AJ 1985 The parasympathetic neuroeffector junction of the heart. Pharmacol Rev 37:1-24

26. Friedman WF, Buccino RA, Sonnenblick EH, Braunwald E 1967 Effects of frequency of contraction and ionic environment on the responses of heart muscle to acetylcholine. Circ Res 21:573-582

27. Streb H, Irvine RF, Berridge MJ, Schulz I 1983 Release of $\mathrm{Ca}^{2+}$ from a nonmitochondrial intracellular store in pancreatic acinar cells by inositol-1,4,5triphosphate. Nature 306:67-69

28. Hirata M, Suematsu E, Hashimoto T, Hamachi T, Koga T 1984 Release of $\mathrm{Ca}^{2+}$ from a non-mitochondrial store site in peritoneal macrophages treated with saponin by inositol 1,4,5-triphosphate. Biochem J 223:229-236

29. Volpe P, Salviati G, DiVirgilio F, Pozzan T 1985 Inositol 1,4,5-triphosphate induces calcium release from sarcoplasmic reticulum of skeletal muscle. Nature 316:347-349

30. Hashimoto T, Hirata M, Itoh T, Kanmura Y, Kuriyama H 1986 Inositol 1,4,5triphosphate activates pharmacomechanical coupling in smooth muscle of the rabbit mesenteric artery. J Physiol (Lond) 370:605-618 